\title{
Educomunicação em praticas de educação ambiental: o uso de documentários na educação básica
}

Karla Emanuelle Carneiro Gonçalves Bonfadini k manuzinha@hotmail.com 000-0002-6216-6976

Centro Federal de Educação Tecnológica Celso Suckow da Fonseca, Rio de Janeiro, Brasil

\section{Danielle Cristina Duque Estrada}

Borim

danideborim@yahoo.com.br

0000-0002-1716-8809

entro Federal de Educação Tecnológica kow da Fonseca, Rio de Janeiro, Brasil

Marcelo Borges Rocha

ochamarcelo36@yahoo.com.br 0000-0003-4472-7423

Centro Federal de Educação Tecnológica Celso Suckow da Fonseca, Rio de

Janeiro, Brasil

\section{RESUMO}

As discussões relacionadas às questões ambientais são recentes e é praticamente consenso que as reuniões internacionais promovidas pela UNESCO e PNUMA são marcos que passaram a atribuir significados e sentidos à Educação Ambiental (EA) em todo o mundo. Nesse contexto, a EA foi se delineando como um instrumento de resistência à crise ambiental e como uma ferramenta que atua em prol da Educomunicação. Assim, o presente estudo objetivou analisar o potencial didático de documentários ambientais em atividades com estudantes do Ensino Fundamental. Para isso, desenvolveram-se oficinas utilizando documentários, com aplicação de um mesmo questionário antes e depois das mesmas. A finalidade desse instrumento de coleta de dados foi ter parâmetros para examinar como se deu a ressignificação dos conteúdos abordados nos documentários por parte dos alunos. Após a análise do material coletado, observou-se que o uso de documentários ambientais, como um recurso pedagógico em oficinas de Educação Ambiental, contribuiu para motivar e sensibilizar os alunos.
\end{abstract}

PALAVRAS-CHAVE: Educação Ambiental. Educação Básica. Documentários Ambientais Educomunicação. 


\section{INTRODUÇÃO}

As discussões relacionadas às questões ambientais no mundo são recentes e a década de 60 pode ser considerada um marco quanto à origem das preocupações no que diz respeito aos problemas ambientais. Em meio à marcha desenfreada pelo crescimento econômico e as intervenções humanas nos ecossistemas terrestres, a Educação Ambiental (EA) foi sendo delineada ao longo dos tempos e constituindo-se enquanto movimento de mudança e resistência frente à crise ambiental, nos mais diversos âmbitos e situações, como: reuniões internacionais, espaços escolares, grupos ecológicos, organizações não governamentais e comunidades autônomas. Para Leff,

Esta mudança de paradigma social leva a transformar a ordem econômica, política e cultural, que, por sua vez, é impensável sem uma transformação das consciências e dos comportamentos das pessoas. Nesse sentido, a educação se converte em um processo estratégico com o propósito de formar os valores, as habilidades e as capacidades para orientar a transição na direção da sustentabilidade (LEFF, 1999, p. 112).

Conforme concluiu Freitas (2012), é praticamente um consenso que as grandes reuniões internacionais promovidas pela UNESCO e Programa Nacional das Nações Unidas para o Meio Ambiente (PNUMA), como: o Clube de Roma (1968), a Conferência de Estocolmo (1972), Conferência de Belgrado (1975), Conferência de Tbilisi (1977), Conferência de Moscou (1987), a II Conferência Mundial para o Meio Ambiente e Desenvolvimento - Eco-92 no Rio de Janeiro, a Cúpula Mundial sobre o Desenvolvimento Sustentável (2002) em Joanesburgo, e a Conferência das Nações Unidas sobre Desenvolvimento Sustentável - Rio+ 20, são marcos que passaram a atribuir significados e sentidos à Educação Ambiental em todo o mundo.

Segundo a Política Nacional de Educação Ambiental (Lei no 9795/1999, Art. 1ํ), a EA é uma dimensão da educação que atua no desenvolvimento social e tem como um dos seus objetivos principais potencializar as atividades humanas tornando-as mais plenas de prática social e de ética ambiental. Nesse contexto, a Comunicação e a Educação são peças essenciais nas relações sociais e no desenvolvimento humano, e o encontro dessas duas ciências criou um novo instrumento no campo do saber: a Educomunicação.

A Educomucanicação é compreendida como um conjunto de ações no âmbito educacional que envolve a democratização da produção e de gestão da informação nos meios de comunicação; se apropriando dos mais diversos materiais que podem ser utilizados para o desenvolvimento e exploração de múltiplas propostas na pedagogia escolar. Segundo Tassara (2008, p. 80), Educomunicação é:

\footnotetext{
Processo de comunicação com intencionalidade educacional expressa e que envolve a democratização da produção e de gestão da informação nos meios de comunicação em seus diversos formatos, ou na comunicação presencial. Educomunicação pode ser definida, também, nas práticas educativas que visam levar à apropriação democrática e autônoma de produtos de comunicação, por meio dos quais os participantes passam a exercer seu direito de produzir informação e comunicação.
} interferências de outras ferramentas, como as tecnologias de informação. No 
mundo globalizado, a disseminação da ciência e de seus avanços tecnológicos se torna de grande importância para a democratização do conhecimento produzido, tornando mais acessível não só o objeto fruto desse desenvolvimento, mas também a discussão dos benefícios e, porque não dos malefícios que tal avanço causa a sociedade.

Em meio a esse progresso, o mundo contemporâneo passou a acreditar que através da ciência e da tecnologia, se resolveria todos os problemas da humanidade, sendo elas (ciência e tecnologia) consideradas divindades (SANTOS; PEREIRA, 2012).

Para Bazzo (1998), essa situação nos chama a atenção para a lógica do comportamento humano, que passou a ser da lógica da eficácia tecnológica e suas razões para as razões da ciência. Sobre uma consequência dessa visão, o mesmo autor cita a supervalorização da ciência e da tecnologia, o que gera a ilusão de que todos os problemas serão resolvidos pelo desenvolvimento de ambas. Essa influência científico-tecnológica acaba refletindo-se na educação, isso porque esse cenário tem levado a uma abordagem educacional que privilegia a integração dos conteúdos científicos aos aspectos políticos, econômicos, sociais e ambientais.

Segundo Santos e Mortimer (2002), esse mesmo cenário acentuou-se nas últimas décadas, principalmente devido ao agravamento das questões ambientais e dos excessos tecnológicos. Isso de certa forma propiciou um ambiente ideal para o surgimento da EA.

Sendo assim, o objetivo deste trabalho foi analisar o potencial didático de documentários ambientais desenvolvidos pela equipe do Projeto Conexão Ambiental, os quais foram exibidos em oficinas de educação ambiental para estudantes do Ensino Fundamental.

\section{A EDUCAÇÃO AMBIENTAL NA EDUCAÇÃO BRASILEIRA}

Dentre os marcos legais que regulamentaram a EA no Brasil, podemos citar a Constituição Federal de 1988, a Lei no 9.795/99, que estabeleceu a Política Nacional de Educação Ambiental - PNEA, e o Programa Nacional de Educação Ambiental - ProNEA.

Em conformidade com os desdobramentos mundiais acerca das temáticas ambientais, o Brasil firmou importantes documentos no âmbito internacional, dentre eles cita-se o documento resultante da Conferência Intergovernamental de Educação Ambiental de Tbilisi, que foi promovida na antiga União Soviética, em outubro de 1977. Sua organização ocorreu a partir de uma parceria entre a UNESCO e o Programa de Meio Ambiente da ONU (PNUMA). Nesse encontro foram formulados objetivos, definições, princípios e estratégias para a Educação Ambiental que até hoje são adotados em todo o mundo.

Em 1981 foi criada a Lei no 6.938/81 que dispôs sobre a Política Nacional do Meio Ambiente, que tinha como objetivo: 
As questões ligadas ao meio ambiente foram introduzidas no panorama de educação no Brasil por meio dos Parâmetros Curriculares Nacionais (BRASIL, 1997), como tema transversal, a ser trabalhado permeando todas as áreas do conhecimento escolar. Para Sato (2003, p. 24):

O ambiente não pode ser considerado um objeto de cada disciplina, isolado de outros fatores, ele deve ser abordado como uma dimensão que sustenta todas as atividades e impulsiona os aspectos físicos, biológicos, sociais e culturais dos seres humanos.

Ressaltando, assim, que a inclusão da temática ambiental nos currículos escolares deve acontecer a partir de atividades diferenciadas, as quais possam conduzir os alunos a serem agentes ativos no processo de formação de conceitos.

Nessa perspectiva, o uso de materiais sobre temas ambientais, em sala de aula, no processo de ensino e aprendizagem podem servir como fonte de informação. A utilização de materiais diversificados como revistas, jornais, propagandas, filmes e/ou documentários, faz com que o aluno sinta-se inserido no mundo a sua volta (BRASIL, 1997).

\section{EDUCOMUNICAÇÃO E EDUCAÇÃO AMBIENTAL}

O termo comunicação tem raiz grega na palavra Koinooni que significa comunidade. Em latim, o vocábulo communis, que quer dizer "o que é de todos", Ihe atribui o mesmo sentido. $O$ ato de educar se faz possível pelo intercâmbio de palavras que fluem através de mensagens, nas quais os interlocutores se interrelacionam em uma comunidade. Assim, podemos concluir que a educação e a comunicação compartilham da mesma base cultural, que propicia as interações humanas e suas trocas culturais.

Segundo Sierra (2000, p. 170), o estudo da articulação entre Comunicação e Educação se torna relevante devido à crescente importância que a mídia e o desenvolvimento das tecnologias eletrônicas vêm adquirindo no processo de produção e da socialização da cultura com o consequente deslocamento da escola como fonte única de conhecimento e a indicação das novas tecnologias como "[...] medios privilegiados de interacción simbólica y socialización”.

Para entender a história dos processos de educação e de comunicação, especialmente na América Latina, faz-se necessário recorrer à escola freiriana que desenvolveu ensinamentos sólidos para a concepção de um modelo inovador e democrático de "educomunicar".

Freire (1978) abalou as estruturas vigentes e elitistas da educação tradicional quando pregou suas ideias dialógicas, libertadoras e democráticas. Assim, o precursor brasileiro da Educomunicação propôs, entre outras ideias, uma educação popular com o intermédio de novas mídias tecnológicas em espaços formais e informais. Um visionário, o autor sugeriu em seu projeto educacional que o fim da opressão e das desigualdades sociais se daria por meio de uma consciência histórica crítica. Com seus pensamentos democráticos, inaugurou um método oposto ao que transmitia de forma vertical e hierárquica os conteúdos, para Freire (1983, p. 78-79) “o educador já não é mais o que apenas educa, mas o que enquanto educa, é educado, em diálogo com o educando que, ao ser educado, também educa. (...) Os homens se educam em comunhão, mediatizados pelo 
mundo", assim, conforme a sua base metodológica, mestre e aluno são detentores do saber e devem compartilhá-lo.

Dessa forma, os meios que disseminam o saber devem ser utilizados como ferramentas voltadas para as ações de cidadania que empoderam os movimentos autônomos e democráticos de certo indivíduo ou comunidade.

Ainda dentro desse contexto, Morán (1995) define que:

O vídeo é sensorial, visual, linguagem falada, linguagem musical e escrita. Linguagens que interagem superpostas, interligadas, somadas, nãoseparadas. Daí a sua força. Somos atingidos por to - dos os sentidos e de todas as maneiras. O vídeo nos seduz, informa, entretém, projeta em outras realidades (no imaginário), em outros tempos e espaços (MORÁN, 1995, p. 28).

Portanto, entende-se a Educomunicação como uma tecnologia em prol da EA, uma vez que o uso dessa ferramenta lúdica e interativa aproxima educandos de educadores, oferecendo uma infinidade de materiais que podem ser utilizados para o desenvolvimento e exploração das mais diversas propostas no âmbito da educação. É então um novo campo de intervenções sociais, no qual os processos de educação e de comunicação se encontram em aspectos práticos e teóricos, ampliando horizontes, criando novas possibilidades e produzindo um novo comunicar em espaços formais e informais.

Nessa lógica, a EA vem firmando seu importante papel na contribuição da formação do indivíduo no exercício da cidadania. Para Dias (2000), a EA foi pensada no âmbito educativo, por meio de sua inserção no conteúdo e na prática escolar, orientada para a resolução de problemas concretos do meio, através de um enfoque interdisciplinar e de uma participação ativa e responsável de cada indivíduo e da coletividade.

\section{METODOLOGIA}

\subsection{Coleta de dados}

A pesquisa foi desenvolvida com 90 alunos de uma instituição particular situada no município do Rio de Janeiro. O público alvo foram estudantes das seguintes turmas: uma do sexto ano, duas do sétimo ano e uma do oitavo ano do Ensino Fundamental. Para sistematização da pesquisa, foram elaborados questionários compostos de cinco questões abertas, relacionadas a cada documentário.

Os questionários que foram aplicados nessas oficinas eram compostos das mesmas perguntas, porém com objetivos diferentes. No questionário préatividades, avaliaram-se os conhecimentos prévios dos estudantes a respeito de questões ligadas a temáticas como: sustentabilidade, biodiversidade e relação homem e natureza; e no questionário pós-atividades, o objetivo foi investigar a percepção dos alunos em relação ao material apresentado, assim como obter parâmetros para analisar como se deu a ressignificação dos conteúdos por parte dos mesmos. 
As atividades ocorreram em março de 2014, através de três oficinas pedagógicas. O primeiro vídeo exibido foi "Lixo de Nós Todos", para uma turma do sexto ano. Em seguida foi veiculado o documentário "Água que Preciso Sempre", para uma turma de sétimo ano. Os vídeos tinham duração média de cinco (5) minutos. E, por último, foi realizada mais uma oficina com a apresentação do curta metragem "Guanabara de Quem?". O documentário tinha o mesmo tempo médio de duração dos anteriores.

Antes da exibição dos documentários, foi feito um brainstorming, ou seja, uma dinâmica para levantar as concepções dos alunos acerca dos temas abordados em cada documentário, de forma que estimulasse o pensamento crítico dos mesmos. Nessa atividade eram apresentados objetos que tinham alguma relação com o tema central de cada um dos documentários, e, então, os alunos eram incentivados a apresentar os seus pontos de vista, que foram registradas na lousa.

Após essa dinâmica, passava-se para a apresentação do material audiovisual, e em seguida, retomavam-se os conceitos e palavras atribuídas aos objetos e discutia-se o tema articulando o conhecimento prévio dos estudantes às informações contidas nos documentários.

\subsection{Produção dos vídeos e oficinas}

Os vídeos foram desenvolvidos pela equipe de trabalho do Projeto Conexão Ambiental ${ }^{1}$, em um breve resumo sobre o desenrolar do trabalho do grupo, destacam-se aqui os principais acontecimentos - no mês de julho foram convocadas as primeiras reuniões nas quais se discutiram os objetivos do projeto, o cronograma das atividades e o levantamento bibliográfico de documentos com temáticas sobre a EA. Em agosto, definiram-se as estruturas dos documentários que abordaram as temáticas centrais: sustentabilidade, relação homem-natureza e biodiversidade. Concomitantemente a essa etapa realizaram-se a divisão dos grupos de trabalho e a construção dos roteiros, os quais tiveram como foco os seguintes locais para a realização da captação das imagens: 1. Baía de Guanabara; 2. Rio Guandu; 3. CEFET e suas adjacências.

Visando obter um material audiovisual de qualidade nas gravações, foram programadas oficinas de capacitação na TV CEFET, que ocorreram no mês de setembro com o grupo de alunos envolvidos no projeto, nas quais foram repassadas noções básicas sobre produção de vídeos e o manuseio das suas ferramentas.

Nos meses de outubro e novembro foram realizados encontros nos quais se dividiu as equipes de trabalho em: direção, produção, edição e captação de imagens. Também foram feitas as locuções dos videodocumentários, as primeiras entrevistas e filmagens.

Dezembro e janeiro foram dedicados para as atividades de gravação dos roteiros "Guanabara de Quem?", "Lixo de Nós Todos" e "Água que Preciso Sempre". As filmagens dos documentários se estenderam até o mês de fevereiro e em paralelo ocorreram os primeiros trabalhos de edição de imagens na TV CEFET.

No mês de março a equipe de produção contatou o colégio Bennet, no qual foram aplicadas as oficinas de educomunicação. As primeiras atividades ocorreram no dia 18 de março de 2014, das 07h às $12 \mathrm{~h}$ por meio de duas oficinas pedagógicas. 
O primeiro vídeo exibido foi "Lixo de Nós Todos" para uma turma do sexto ano. Em seguida foi veiculado o documentário "Água que Preciso Sempre" para uma turma de sétimo ano. No dia 21 de março de 2014, das 07h às 08:30h foi realizada mais uma oficina com a apresentação do curta metragem "Guanabara de Quem?".

Por fim, os meses de abril, maio e junho foram dedicados para avaliação das oficinas de EA e para a redação de trabalhos científicos sobre o potencial pedagógico dos vídeos na sala de aula.

\section{3. Análise dos dados}

Nesse trabalho utilizou-se o método de Análise de Conteúdo de Bardin (1977), que, por meio de técnicas, procura identificar os principais conceitos ou temas abordados em um determinado material de estudo.

Com isso, para avaliar o potencial dos vídeos e como eles foram ressignificados pelos alunos, foram seguidas algumas fases da metodologia da referida autora que apresenta quatro passos importantes, a saber:

I) Fase de leituras flutuantes,

II) Seleção das unidades de análises,

III) Categorização,

IV) Tratamento dos resultados, interpretação.

Assim, como primeiro procedimento de apreciação do material, realizou-se uma leitura flutuante com o intuito de apreender e organizar de forma não estruturada aspectos importantes para as próximas fases da análise. Na leitura flutuante, toma-se contato com os documentos a serem analisados, conhece-se o contexto e deixa-se fluir impressões e orientações (BARDIN, 1977). Posteriormente, na etapa de codificação, buscou-se orientação nas questões das pesquisas e realizou-se uma seleção das unidades de análises o que gerou a escolha dos temas. Na etapa seguinte, foram criadas as categorias, que segundo Bardin (1977), é uma operação de classificação de elementos constitutivos de um conjunto por diferenciação e, seguidamente, por reagrupamento segundo o gênero para posterior análise dos resultados e discussões.

É importante ressaltar que os alunos que participaram dessa pesquisa foram identificados por letras para que, assim, as suas identidades fossem preservadas.

\section{RESULTADOS E DISCUSSÕES}

Na turma do sexto ano apresentou-se o documentário "Lixo de Todos Nós". Diante do estudo detalhado dos questionários que antecederam a exibição dos vídeos, podem-se analisar as considerações prévias dos estudantes para a pergunta "Para onde vai o lixo jogado nos rios?"

Foram observadas respostas variadas que originaram diferentes categorias conforme a percepção dos alunos. Sendo assim, 48\% acham que o lixo jogado nos rios vão para praias, mares, oceanos ou permanecem nos próprios rios, como disseram os alunos A e B, respectivamente "Ele vai para os mares e oceanos"; "Ele segue até a foz e despenca em um oceano, ou então fica parado no rio só poluindo 
ele". Já $17 \%$ dos alunos acreditam que o lixo segue para reciclagem ou lixão. $\mathrm{Na}$ categoria "Outros", representada por $14 \%$ dos participantes, os estudantes D e E opinaram que o lixo vai "Para os bueiros"; ou ainda "Vai parar nos animais aquáticos do mar" e $10 \%$ acreditam que o lixo vai para os esgotos. Por fim, $11 \%$ dos perguntados não souberam responder ou se abstiveram.

$\mathrm{Na}$ aplicação do mesmo questionário após a apresentação do vídeo, foram obtidos os seguintes comentários para a pergunta "Para onde vai o lixo jogado nos rios?". A maioria, $64 \%$ dos alunos responderam que vai para o rio, para o mar e para Baía de Guanabara; a categoria "Reciclagem ou Lixão" se repetiu, e foi composta por $23 \%$ dos estudantes. Já $10 \%$ dos participantes se enquadraram na categoria "Outros", como as respostas dos alunos F e G "Vai para o esgoto e depois para o mar"; "Para o ralo - esgoto - rio- Baía de Guanabara". A categoria dos alunos que não responderam caiu para $3 \%$.

Segundo o IBGE (2000), o Brasil coleta 228.413 toneladas de lixo por dia, que são destinados para unidades distintas, como: lixões, vazadouros em áreas alagadas, aterros sanitários, estação de triagem, dentre outros. No entanto, como podemos perceber, embora haja coleta, muitas vezes esta ocorre de forma insatisfatória, como no caso dos vazadouros e dos lixões. Devemos ainda considerar o lixo não coletado e descartado de maneira indiscriminada pela população em vias públicas, córregos e rios, poluindo e contaminando os corpos hídricos; e inviabilizando atividades como a pesca, o lazer e a dessedentação de animais. Grande parte dos rios deságua diretamente nos mares e oceanos, como no caso dos rios fluminenses e isso significa que os mares e oceanos recebem todo o aporte de poluição carreado pelos rios. Daí a importância desse debate em sala de aula, pois oportuniza que os alunos entendam sobre a problemática da falta de tratamento adequado para resíduos sólidos e efluentes, que são as principais fontes de poluição dos recursos hídricos.

Para a pergunta "Qual a diferença entre reciclagem e reutilização", segundo os dados coletados previamente por meio dos questionários, $72 \%$ dos alunos compreendem que existem diferenças entre os dois processos, enquanto $7 \%$ acreditam que sejam iguais e, $21 \%$ não souberam responder ou se abstiveram, o que representou uma parcela significativa da amostra.

Ao analisar o conteúdo das respostas dos que apontaram ser diferente a reciclagem da reutilização, percebe-se que parte dos alunos, $51 \%$, entende que existem distinções, mas não sabem definí-las corretamente, como podemos observar nas falas dos alunos A, B, C e D "A reciclagem você recicla ela para outra coisa e a reutilização você vai reutilizar a garrafa"; "A reciclagem você recicla e a reutilização você reutiliza"; "Reciclagem é como o primeiro passo de reutilização porque "nos" reciclamos e depois se quisermos podemos reutilizar essa reciclagem"; "Reciclagem é tipo uma indústria que separa todo o lixo, e esse lixo que eles "separa" é"reaproveitados" para outra coisa". Já outra parcela dos estudantes, $21 \%$ explicou com mais clareza a distinção entre as duas atividades, como o aluno E "Quando você recicla você transforma uma coisa em outra e quando reutiliza você fica usando várias vezes".

Partindo para análise dos questionários aplicados após a exibição dos vídeos, percebeu-se uma significativa mudança nas respostas dos alunos. Aumentou para $90 \%$ os que identificaram que a reciclagem e a reutilização são métodos distintos, e diminuiu para $10 \%$ os que não sabiam ou não responderam. Dentre os alunos 
que souberam discernir serem atividades diferentes, podemos assinalar que cresceu para $73 \%$ os que conseguiram descrever com mais propriedade as diferenças entre a reciclagem e a reutilização, enquanto apenas $17 \%$ não apresentaram evolução nas argumentações após a exibição do documentário.

Alguns alunos discorreram sobre a reutilização e reciclagem com definições que se aproximaram do conteúdo que foi veiculado no documentário "Lixo de Nós Todos", e das descrições da literatura científica acerca desse assunto. Podemos concluir nas seguintes respostas dos participantes A e B: "Reciclagem = alterar a forma de um produto para fazer matéria-prima. Reutilizar = reutilizar o material "de novo" como o próprio material ou como um outro"; "Reciclagem é quando você transforma uma coisa em matéria-prima. Reutilização é quando você pode reutilizar a coisa que você ia fazer jogar fora". Diante dos trechos anteriores com as falas dos alunos, podemos observar as semelhanças com a abordagem de Leite (2003) sobre a reciclagem:

\begin{abstract}
A reciclagem é o canal reverso de revalorização em que os materiais constituintes dos produtos descartáveis são extraídos industrialmente transformando-os em matérias-primas secundárias ou reciclados, que serão reincorporados à fabricação de novos produtos (LEITE, 2003, p.71)
\end{abstract}

Para Vale (1995), o ato de reciclar, isto é, refazer o ciclo, permite trazer de volta à origem sob a forma de matéria-prima secundária aqueles materiais que não se degradam facilmente e que podem ser processados mantendo suas características básicas. Portanto, reciclagem não deve ser confundida com reutilização de materiais ou reuso de alguns artigos, como vasilhames e garrafas retornáveis. Nesse caso a reciclagem não existe, o que existe é a reutilização do mesmo artigo, na mesma forma que foi originalmente produzido.

Podemos inferir que as respostas mais elaboradas e reflexivas dos alunos foram possíveis a partir da sensibilização do documentário "Lixo de Nós Todos".

O vídeo "Água que Preciso Sempre" foi exibido para a turma do sétimo ano. Antes da exibição do curta, foi aplicado o questionário com a seguinte pergunta: "Qual importância da água para a vida dos seres humanos?". Observou-se que $48 \%$ dos estudantes afirmaram que era importante para sobreviver; $17 \%$ consideraram indispensável para as atividades de higiene e alimentação; $10 \%$ citaram que é necessária para obter energia e saúde; $16 \%$ como o aluno A, opinaram "Para não desidratar" e outros 4\%, conforme citou o aluno B "Para não haver disputa econômica". Apenas 5\% dos alunos não responderam ou se abstiveram.

No questionário posterior a exibição do vídeo as categorias e subcategorias se repetiram com porcentagens semelhantes. No entanto, esse não é um indicativo que o vídeo não sensibilizou os alunos, mas sugere que os mesmos já possuíam informações e conhecimento preliminares sobre a temática abordada, uma vez que desde cedo aprendemos em casa e no ambiente escolar a importância da água para a manutenção da vida.

Reiterando o exposto acima, Kuhnen e Becker (2010), em um trabalho realizado com jovens e adultos sobre a importância da água, comentam que: 
responderem à questão "O que lhe vêm à cabeça ao se falar em água?". "Quando acordo eu agradeço por ela existir"; "Sem água o que seria de nós?"; "A maior riqueza do mundo é a água", e ainda, "Saúde, vida, sem água não nasce nada", ou, "Água significa tudo, sobrevivência, vida"; e (b) em termos de atividades relativas ao cotidiano ( $32 \%$ da amostra) como utilização em tarefas diárias de limpeza, entre outras, como por exemplo o entrevistado diz que ao pensar em água pensa em: "sede; limpeza; alimentação; poluição; lembro de chimarrão [...] serventia pra tudo; banho (KUHNEN \& BECKER, 2010 p. 163).

Ainda analisando o questionário destinado para a turma do sétimo ano, mas agora referente à pergunta "Qual a importância do tratamento de água para o consumo humano?" encontramos, no questionário prévio, as seguintes categorias e percentuais: $37 \%$ entendem que é importante para evitar doença e infecção; $26 \%$ acreditam que o tratamento é importante para remover sujeira e contaminação; $16 \%$ escreveram que é necessário para remover bactéria e $11 \%$ acreditam que é indispensável para ficar potável. A categoria dos que não responderam foi representada por $10 \%$ dos estudantes.

Analisando as respostas destes alunos após a exibição do vídeo, para a pergunta "Qual a importância do tratamento de água para o consumo humano?", observamos que $32 \%$ dos participantes não souberam ou se abstiveram de responder o questionamento. Esse percentual foi uma surpresa, tendo em vista que no questionário prévio apenas $10 \%$ dos alunos preencheram essa categoria. Contudo, podemos considerar algumas hipóteses para esse resultado: a) a não compreensão dos estudantes sobre o tópico "tratamento de água" abordada no documentário, ou seja, o vídeo foi inconclusivo e não sensibilizou uma parcela dos alunos ao apresentar essa temática; b) os participantes deixaram de responder por falta de interesse ou por outros motivos.

No entanto, outros $32 \%$ dos alunos opinaram que o tratamento é importante para evitar doenças e infecções; $16 \%$ "Para não morrer", conforme respondeu o aluno $\mathrm{A} ; 10 \%$ responderam que serve para remover sujeira e contaminação e, por fim, 10\% acreditam que é necessário para "remover bactérias", como disse o aluno B. As categorias foram semelhantes as do pré-questionário e o teor das respostas também.

De forma geral, percebeu-se que os alunos entendem que a água dos mananciais destinados para 0 abastecimento humano pode conter microrganismos causadores de doenças, além de contaminantes e partículas que precisam ser removidas no tratamento.

Sá, em pesquisa realizada no ano de 2013, na cidade de Curitiba, obteve alguns resultados parecidos com a presente pesquisa, referente á opinião de crianças sobre o tratamento da água.

(...) através da análise dos questionários verificou-se que os alunos participantes do projeto Vida à Água possuem um entendimento melhor sobre o tratamento de água. Este fato pode ser evidenciado no terceiro item, onde $35 \%$ dos participantes responderam que é necessário tratar a água para matar os microrganismos e em contrapartida $20 \%$ dos não participantes tiveram esta resposta. Portanto, o objetivo da atividade lúdica denominada "Gotinha" como já citado anteriormente foi alcançado" (SÁ, 2013, p.105). 
apresentação do vídeo $91 \%$ dos estudantes afirmaram que sim. Apenas $9 \%$ dos alunos não souberam responder.

Na subcategoria "Cor e cheiro"' que foi representada por $21 \%$ dos participantes, os alunos A, B, C e D escreveram, respectivamente: "Sim, pois ela está cor preta e tem lixo"; "Sim. Ao passar "la"muitas pessoas só passar "la" sente um cheiro tipo de "coco";"Sim, porque quando passamos próximo a mesma o cheiro não é muito agradável e acaba denunciando a poluição da Baía"; "Sim, eu acho, eu sempre vejo lixo nela e também observo que ela não é mais azul, mas que ela tem um tom esverdeado por causa do lixo".

É interessante perceber que o conceito de qualidade de água foi descrito pelos alunos de acordo com as suas percepções sensoriais. Como evidenciado por Santos et al. (2008), geralmente o conhecimento e o saber popular sobre qualidade de água estão intimamente relacionados com a aparência e a cor que ela apresenta.

No questionário posterior a exibição do documentário percebeu-se que $100 \%$ dos alunos afirmaram que a Baía de Guanabara está poluída. Também foi possível observar que os argumentos dos participantes foram enriquecidos, como consequência do conteúdo veiculado no vídeo "Guanabara de Quem?", como se confirma nas falas dos alunos E, F e G, respectivamente: "Mas a pergunta é: será que vai dar pra limpar até 2016?"; "Sim, pelas indústrias que jogam o lixo nas águas e poluem as pessoas irresponsáveis que não pensam no futuro"; "Acho, pois rios, canais, galerias estão poluídos também e os canais, rios "desabam" na baía colaborando na poluição, os esgotos e outros tipos ajudam muito na poluição"; "Sim, pois o "olho" dos navios no mar, detritos, lixo, sacolas etc." na Baia de Guanabara".

Em outro questionamento, buscou-se investigar como os alunos entendiam a poluição hídrica. Mais da metade dos alunos, 57\%, responderam que a poluição hídrica tem a ver com a poluição de rios, lagos e mares, $27 \%$ dos estudantes comentaram em suas respostas que não sabiam, enquanto $16 \%$ se abstiveram de responder.

Analisando a mesma pergunta após a exibição do documentário "Guanabara de quem?", percebemos que houve o crescimento para $90 \%$ no número de alunos que disseram entender o que é poluição hídrica "É uma poluição dos rios, canais e etc.", resposta do aluno A; "Entendo que é a poluição dos esgotos não tratados, lixo e tudo que é despejado no mar", afirmação do aluno B e, por fim, o estudante C "É a poluição nas águas como exemplo a Baía de Guanabara". Somente 10\% deixaram a pergunta em branco.

Segundo Suetônio Mota (1995), entende-se por poluição hídrica a alteração das propriedades físicas, químicas e biológicas das águas, que possa importar em prejuízo à saúde, à segurança e ao bem-estar das populações e ainda comprometer a sua utilização para fins agrícolas, industriais, comerciais, recreativos e, principalmente, a existência normal da fauna aquática.

Assim, diante dos resultados acima podemos inferir que o vídeo "Guanabara de quem?" cumpriu o seu papel sensibilizador para a temática poluição hídrica. 
Após finalizar a análise do material coletado, pode-se inferir que a Educomunicação, neste caso específico do uso de documentários, configura-se como uma ferramenta eficiente de divulgação em atividades de EA na educação básica, cumprindo o papel de expandir horizontes, oportunizando os alunos a fomentar discussões e quebrar paradigmas.

Assim, diante das interpretações das mensagens contidas nos instrumentos de coleta de dados, no geral, podemos afirmar que houve relevante evolução nas reflexões e nos argumentos dos estudantes depois que os mesmos puderam "adentrar" no universo interativo e multissensorial dos vídeos, que funcionam como pontes entre o saber e o aprendiz.

Diante do exposto, entende-se que é necessário intensificar a implantação de projetos de EA nas escolas, com o intuito de multiplicar os bons resultados e de promover "uma alfabetização" que permita que os alunos tenham cada vez mais acesso ao conhecimento que os capacite para o enfrentamento das problemáticas socioambientais. 


\title{
Educommunication practices in environmental education: the documentary use in basic education
}

\begin{abstract}
Discussions related to environmental issues are recent and is almost a consensus that large international meetings organized by UNESCO and PNUMA are milestones that started to assign meanings and senses to Environmental Education (EE) worldwide. In this context, EE has been taking shape as an instrument of resistance to the environmental crisis, and as a tool that works in favor of Educomunication. In this perspective, the present study aimed to analyze the didactic potential of environmental documentaries in activities with elementary school students. For this, workshops using documentaries, applying the same questionnaire before and after the same have been developed. The goal was to have the repetition parameters to examine how was the reframing of content by students. After data analysis, it was observed that the use of environmental documentaries, as a teaching tool in environmental education workshops, contributed to greater awareness and motivation on the part of students, thereby fostering the learning of concepts and issues related to the theme environmental.
\end{abstract}

KEYWORDS: Environmental Education. Environmental Documentaries. Educomunication. 


\section{NOTAS}

10 Projeto Conexão Ambiental coordenado pelo professor Dr. Marcelo Rocha foi desenvolvido no período de julho de 2013 a junho de 2014 por uma equipe composta de 11 integrantes; sendo dois professores, um produtor artístico (colaborador), e nove discentes do curso de Tecnologia de Gestão Ambiental do Centro Federal de Educação Tecnológica Celso Suckow - CEFET/RJ, três destes discentes foram bolsistas de iniciação científica pelo Conselho Nacional de Desenvolvimento Científico e Tecnológico - CNPq. O objetivo do projeto foi produzir documentários educativos direcionados para a área de educação socioambiental, a fim de serem apresentados para alunos do Ensino Fundamental.

\section{REFERÊNCIAS}

BARDIN, L. Análise de Conteúdo. Lisboa, Portugal; Edições 70, LDA, 1977.

BAZZO, W. A. Ciência, tecnologia e sociedade: e o contexto da educação tecnológica. Florianópolis: EDUFSC, 1998.

BRASIL. Lei $n$ o 6.938, de 31 de agosto de 1981. Política Nacional do Meio Ambiente. Brasília, DF, 1981.

BRASIL, Constituição da República Federal do Brasil de 1988. Disponível em: $<$ http://www.planalto.gov.br/ccivil 03/constituicao/ConstituicaoCompilado.h $\underline{\mathrm{tm}}$.> Acesso em 06 de jan. 2014

BRASIL. Lei $n^{\circ}$ 9.433, de 8 de janeiro de 1997. Política Nacional e Sistema Nacional de Gerenciamento de Recursos Hídricos. Brasília, DF, 1997

CANADÁ, Comissão sobre Meio Ambiente e Desenvolvimento Sustentável XI Assembléia Geral, Confederação Parlamentar das Américas, 2011.

DAVIS, C. OLIVEIRA, Z. M. R. Psicologia da Educação. 3a ed. Editora Cortez, 2010.

DIAS, G. F. Educação ambiental: princípios e práticas. 6ำ ed. São Paulo: Gaia, 2000. 551

FREIRE, P. Pedagogia do Oprimido. Rio de Janeiro: Paz e Terra, 1978.

FREITAS. A utopia compartida e o compartir da utopia: A Educação Ambiental no contexto de uma experiência ecológica integral: a Eco-comunidad del Sur. Rio 
Kuhnen, A. \& Becker, S. M. S. Psico, Porto Alegre, PUCRS, v. 41, n. 2, pp. 160-167, abr./jun. 2010.

LEFF, E. Saber Ambiental. Petrópolis: Vozes, 1999. 112 p.

MORÁN, J.M. "O Uso das Novas Tecnologias da Informação e da Comunicação na EAD: uma leitura crítica dos meios." Palestra proferida no evento "Programa TV Escola-Capacitação Gerentes". Belo Horizonte, 1995.

MOTA, S. Preservação e Conservação de Recursos Hídricos. 2. ed. Rio de Janeiro: ABES, 1995.

Sá, P. Z. de. Análise e avaliação do projeto de educação ambiental "vida e água" voltado à gestão de bacias hidrográficas (Pinhais-PR) / Dissertação Mestrado. 2013.

SANTOS, T. C. dos; PEREIRA, E. G. C. O enfoque CTS e a Educação Ambiental (EA) através de dinâmicas de grupo e aula-passeio: um estudo com licenciandos em Química. In: III Encontro Nacional de Ensino de Ciências da Saúde e do Ambiente Niterói/RJ, 2012.

SANTOS, W. L. P e MORTIMER, E. F. Uma análise de pressupostos teóricos da abordagem C-T-S no contexto da educação brasileira. Ensaio - Pesquisa em Educação em Ciências, v. 2, n. 2, 2002).

SATO, M. Educação Ambiental. São Carlos: Rima, 2003.

SIERRA, F. 2000. El campo de la comunicación educativa. In: Introducción a la teoria de la comunicación. Sevilla, MAD. SOARES, I. O. Sociedade da informação ou da comunicação? São Paulo: Cidade Nova, 2000.

TASSARA, Eda. Dicionário Socioambiental: idéias, definições e conceitos. São Paulo: FAART, 2008. 
Recebido: 26 dez. 2014

Aprovado: 20 mar. 2016.

DOI: $10.3895 /$ rbect.v9n1.2098

Como citar:

BONFADINI, K. E. C. G.; BORIM, D. C. D. E.; ROCHA, M. B. Educomunicação em praticas de educação ambiental: o uso de documentários na educação básica. Revista Brasileira de Ensino de Ciência e

Tecnologia, v. 9, n. 1, p. 326-341, jan./abr. 2016. Disponível em:

<https://periodicos.utfpr.edu.br/rbect/article/view/2098>. Acesso em: xxx.

Correspondência:

Karla Emanuelle Carneiro Gonçalves Bonfadini

Rua General Osório, 1918, n.31, 96400-101- Bagé - Rio Grande do Sul.

Danielle Cristina Duque Estrada Borim

Av. Maracanã, 229, 20271-110, Rio de Janeiro

Marcelo Borges Rocha

Av. Maracanã, 229, 20271-110, Rio de Janeiro

Direito autoral: Este artigo está licenciado sob os termos da Licença Creative Commons-Atribuição 4.0 Internacional.

\section{(c) (1)}

